\title{
Current permissible levels of heavy metal pollutants harm terrestrial invertebrates
}

\author{
Coline Monchanin ${ }^{1}$, Jean-Marc Devaud ${ }^{1}$, Andrew Barron $^{2}$, and Mathieu Lihoreau ${ }^{1}$ \\ ${ }^{1}$ CNRS Délégation Midi-Pyrénées \\ ${ }^{2}$ Macquarie University
}

November 3, 2020

\begin{abstract}
The current decline of invertebrates worldwide is alarming. Several potential causes have been proposed but heavy metals, while being a widespread and major pollutants of air, soils and water, have so far been largely overlooked. Here, we ran a meta-analysis of 527 datasets on the effects of arsenic, cadmium, lead and mercury on terrestrial invertebrates. These four well-studied metals, for which international guidelines exist, significantly impact the physiology and behavior of invertebrates, even at levels below those recommended as 'safe' for humans. Our results call for a revision of the regulatory thresholds to better protect terrestrial invertebrates, which appear to be more sensitive to metal pollution than vertebrates. More fundamental research is needed to improve international guidelines for metal pollutants, and to develop conservation plans to mitigate invertebrate declines and protect ecosystem services.
\end{abstract}

\section{Hosted file}

Heavy metals harm terrestrial invertebrates.pdf available at https://authorea.com/users/ 311198/articles/490580-current-permissible-levels-of-heavy-metal-pollutants-harmterrestrial-invertebrates 